\title{
Effects of acute and long-term bronchodilator treatment on regional lung function in asthma assessed with krypton-81m and technetium-99m-labelled macroaggregates
}

\author{
ANSSI R A SOVIJÄRVI, LAURI PÖYHÖNEN, LIISA KELLOMÄKI, ANTERO MUITTARI \\ From the Departments of Clinical Physiology and Pulmonary Diseases, Tampere University Hospital, \\ Tampere, Finland
}

ABSTRACT We have investigated the effect of acute and long-term bronchodilator treatment on the distribution of ventilation and perfusion in 15 asthmatics using a gamma camera, krypton$81 \mathrm{~m}$ (for ventilation) and technetium-99m macroaggregate (for perfusion). Individual peak expiratory flow (PEF) values before bronchodilation were slightly or moderately below the predicted values. The simultaneous ventilation images (analysed visually) showed areas of delayed ventilation in all patients (mean distribution score on 3-point scale 2.1). After isoprenaline inhalation $(240 \mu \mathrm{g})$ the mean PEF increased by $24 \%$, but the distribution of ventilation remained virtually unchanged in all patients (mean score 2.0 ). Simultaneously defects in perfusion could be seen in all patients (mean score 1.5). After intensive treatment, when the mean PEF increased by a further $29 \%$, the distribution scores of ventilation and perfusion fell to 0.8 and $0 \cdot 9$, respectively. The results indicate that, without intensive and long-term treatment, appreciable inequality of ventilation and perfusion are usual consequences of asthma; and suggest that although larger airways are dilated by isoprenaline inhalations residual bronchial obstruction may still remain in some smaller airways, maintaining uneven distribution. Perfusion disturbances seem to be secondary to changes in regional ventilation.

In asthma, as well as in other obstructive pulmonary diseases, disturbances in the distribution of ventilation are common. This has been clearly demonstrated both indirectly-for example, by analysing the curve of expired nitrogen concentration ${ }^{1}$-and directly with radioactive isotopes and gamma camera. ${ }^{2-6}$ Isotope studies have also revealed that obstructive pulmonary diseases may cause considerable perfusion defects. ${ }^{6-9}$

Acute bronchodilation induced by inhalation of sympathomimetic agents has shown little ability to improve regional impairment in ventilation despite significant reduction of the overall airways obstruction. $^{29}$ Furthermore, bronchodilation produced by inhalation of isoprenaline or salbutamol has not been able to correct hypoxaemia in asthmatics. ${ }^{210}$

Address for reprint requests: Dr Anssi Sovijärvi, University of Helsinki, Lung Function Laboratory, Meilahti Hospital, SF-00290, Helsinki 19, Finland.
There have, however, been no systematic studies in asthma dealing with the effects of long-term bronchodilator treatment on regional disturbances in ventilation or perfusion, although a few cases have been reported in which intensive bronchodilator treatment has substantially diminished the nonuniformity of ventilation. ${ }^{5}$

In this study we have evaluated both the effects of acute bronchodilation, produced by inhalation of isoprenaline, and the effects of intensive long-term bronchodilator treatment on overall airways obstruction and on regional ventilation and perfusion in asthmatics with no notable chronic bronchitis or emphysema. In the assessment of regional ventilation we have used the short-half-life isotope krypton-81 $\left({ }^{81 \mathrm{~m}} \mathrm{Kr}\right)$ facilitating direct imaging with a gamma camera. ${ }^{11}$ Thus visual comparison of the ventilation images with those of regional perfusion, obtained with technetium-labelled-macroaggregated albumin ( $\left.{ }^{99 m} \mathrm{Tc}-\mathrm{MAA}\right)$, was possible. 


\section{Methods}

Fifteen asthmatics were studied, 11 of whom were women. Their ages ranged from 34 to 79 years (mean 52 years). All patients suffered from perennial asthma requiring permanent medication. They had no other significant pulmonary or cardiovascular diseases. Four patients were atopic. In 13 patients the chest radiograph showed linear shadows in isolated areas of the lungs and one patient had small pleural adhesions. Otherwise, the chest radiographic findings were normal. In all patients significant reversibility of bronchial obstruction (change in peak expiratory flow rate (PEF) at least $15 \%$ from the baseline) had been found within one year before the study either on the diurnal follow-up of PEF, on spirometric bronchodilatation tests, or on various bronchial provocation tests (or on two or all three of these). All patients were non-smokers.

The variations of bronchial obstruction were assessed by measuring PEF with a Wright peak flow meter. The best value of at least three successful exhalations was recorded. Regional ventilation and perfusion were studied with a Searle gamma camera (PHO/Gamma IV). Ventilation images were obtained by the use of radioactive krypton- $81 \mathrm{~m}$ isotope eluted from a $\mathrm{Rb}{ }^{81 \mathrm{~m}} \mathrm{Kr}$ generator. The generators used were prepared in the cyclotron of Ábo Akademi, Turku, Finland. The patients inhaled the ${ }^{81 \mathrm{~m}} \mathrm{Kr}$ gas mixed with room air via a three-way valve at a normal respiratory rate and level (tidal breathing). Collection of 80 000-100 000 counts for one image took two to four minutes. The images, which directly represent the distribution of ventilation owing to the short half-life (13 seconds) of ${ }^{81 \mathrm{~m}} \mathrm{Kr},{ }^{11}$ were recorded on polaroid film.

For the imaging of the distribution of pulmonary perfusion ${ }^{99 m}$ Tc-MAA was injected into a cubital vein. We collected 200000 counts for a perfusion image. Ventilation and perfusion images were recorded both in the anterior and in the posterior projection with the subject in the supine position. In each phase of the study the PEF measurements were obtained before the gamma camera studies. Ventilation imaging always preceded perfusion imaging.

During the baseline studies the patients had moderate exacerbations of asthma. In most cases the obstruction was induced by discontinuing the bronchodilator treatment either totally or partially for six to 12 hours. After measurement of PEF and the imaging of ventilation the patients inhaled three puffs of isoprenaline aerosol $(240 \mu \mathrm{g})$ during inspiratory manoeuvres from the functional residual capacity to the total lung capacity level. Three to 10 minutes later measurement of PEF and the imaging of ventilation were repeated and the first perfusion images were obtained. Owing to the long biological half-life of ${ }^{99 m}$ Tc-MAA, perfusion imaging could not be done successively before and after isoprenaline inhalation.

After the acute bronchodilatation study the patients received intensive bronchodilator treatment for one week in hospital. All patients were given oral glucocorticoids in daily doses corresponding to $30-40 \mathrm{mg}$ prednisolone initially, the dose being gradually reduced during the week. In addition, 10 patients received salbutamol aerosol 5-10 mg daily, administered by means of intermittent positivepressure breathing; five used salbutamol metereddose aerosol 0.4-0.8 mg daily; seven oral theophylline, about $600-700 \mathrm{mg}$ daily; six beclomethasone aerosol in daily doses of $400 \mu \mathrm{g}$; and two ipratropium bromide $120 \mu \mathrm{g}$ daily as a metered-dose aerosol.

PEF and gamma camera studies (ventilation and perfusion) were performed after the period of intensive treatment, not later than two to three hours after the last drug doses. Gamma camera pictures were analysed visually by two of the authors independently, who scored the degree of distribution abnormalities from 0 to 3 using the method of Taplin et al: ${ }^{4} 0$ indicates uniform distribution and 1 slight, 2 moderate, and 3 appreciable nonuniformity. In addition, areas with ventilationperfusion mismatch were assessed visually. During the picture analysis the authors did not know at which stage of treatment the pictures were taken. The paired $t$ test and the $\chi^{2}$ test were used in the statistical analyses.

\section{Results}

The mean PEF values ( \pm SD) and the mean distribution scores $( \pm S D)$ of ventilation and perfusion during different stages of the study are shown in the table, which also shows the changes in PEF relative to the baseline ( $\Delta$ PEF) and the statistical significances of all changes. The behaviour of the mean PEF values and of the distribution scores at different stages of therapy are presented graphically in figure 1.

Before bronchodilator treatment individual PEF values were slightly or moderately lower than the reference values. ${ }^{12}$ At this stage regional disturbances of ventilation could be seen in all patients in the gamma pictures obtained with ${ }^{81 \mathrm{~m}} \mathrm{Kr}$; three patients had appreciable defects affecting over half of the pulmonary regions visible in the pictures (score 3 ) and 10 patients had moderate defects (defects of $25-50 \%$, score 2). In 14 patients abnormalities in regional ventilation were observed in both lungs. In most cases the disturbances of ventila- 
Effects of isoprenaline inhalations $(240 \mu \mathrm{g})$ and long-term bronchodilator treatment on peak expiratory flow (PEF) and on the distribution of ventilation and perfusion in 15 patients with asthma*

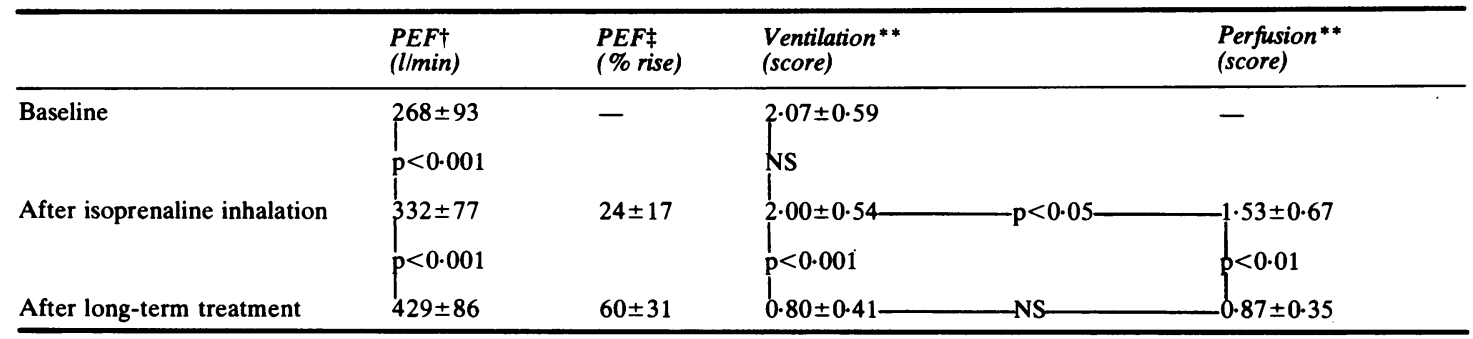

${ }^{*}$ The regional disturbances are assessed according to Taplin et al $(1977)^{4}$ using the score from 0 to $3: 0=$ uniform, $1=$ slightly, $2=$ moderately and $3=$ markedly nonuniform. The figures indicate the mean and standard deviation (SD). In addition, the statistical significance of differences is indicated as probability $(p)$ values.

$\dagger$ Paired $t$ test for statistical comparison.

$¥$ Compared with the baseline.

${ }^{* *} \chi^{2}$ test for statistical comparison.

NS $=$ not significant.

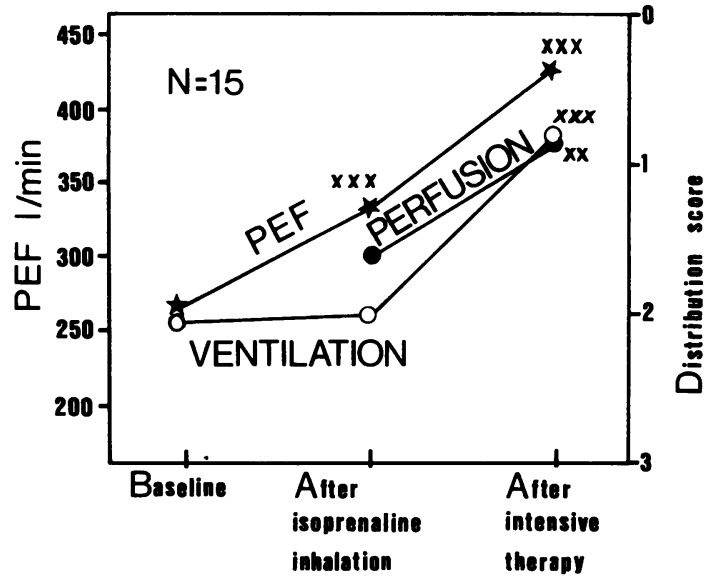

Fig 1 Mean PEF and the mean scores of regional ventilation and perfusion in 15 asthmatic patients during different stages of bronchodilator therapy. The scoring and the statistical methods as in the table. $x=p<0.05, x x x=p$ $<0.001$ when comparing the adjoining stages of the study.

tion could be interpreted as affecting a segment or a smaller lung region. In addition, three patients had ventilation defects affecting a whole lobe.

After inhalation of isoprenaline there was a marked increase in PEF (see table and fig 1) but regional abnormalities in ventilation were appreciably alleviated in one patient only. At the same time, non-uniform perfusion could be found in all patients, the defects being considerable in two and moderate in four patients. Areas with reduced ventilation-perfusion ratios could be detected in 12 patients. Of these, two patients in addition had small areas with increased ventilation-perfusion ratios. Despite this, ventilation and perfusion defects were for the most part located in the same areas. In three patients no ventilation-perfusion mismatching could be seen after the acute isoprenaline inhalation test.

After intensive bronchodilator treatment PEF had increased about $60 \%$ from the baseline and $29 \%$ from the level achieved after administration of isoprenaline. At this stage the defects in distribution of both ventilation and perfusion had also been significantly improved (table and fig 1). In two patients regional lung function was regarded as perfectly normal. In addition, one patient showed uniform ventilation and another patient uniform perfusion. Slight disturbances of regional pulmonary function were still found in 13 patients $(87 \%)$ after long-term bronchodilator treatment. Slight mismatch of ventilation-perfusion ratios were detected at that time in six patients only.

Figures 2 and 3 give an example of the changes in regional lung function during different phases of the bronchodilator treatment.

\section{Discussion}

The use of ${ }^{81 \mathrm{~m}} \mathrm{Kr}$ isotope in gamma camera studies of ventilation distribution defects has proved to be sensitive to even slight regional impairment of ventilation $^{12}$ (see also paper by E Kaplan et al, International Atomic Energy Agency Symposium, Los Angeles, 1976). Thus the detection of appreciable disturbances in regional ventilation in asthmatic patients before active bronchodilator treatment therapy when the degree of overall obstruction was slight or moderate was not unexpected. Nonuniformity of ventilation in asthmatic patients has been found also in some earlier studies with radioactive xenon ${ }^{13-15}$ and with ${ }^{81 \mathrm{~m}} \mathrm{Kr}$. $^{59}$

Our results clearly confirm that the distribution of ventilation does not become more uniform after 


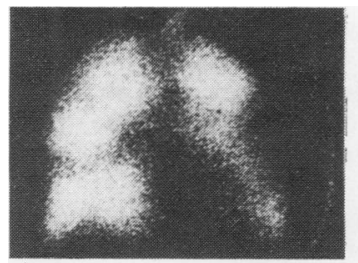

A

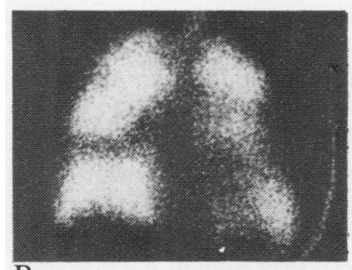

B

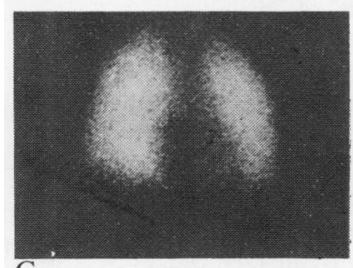

ap
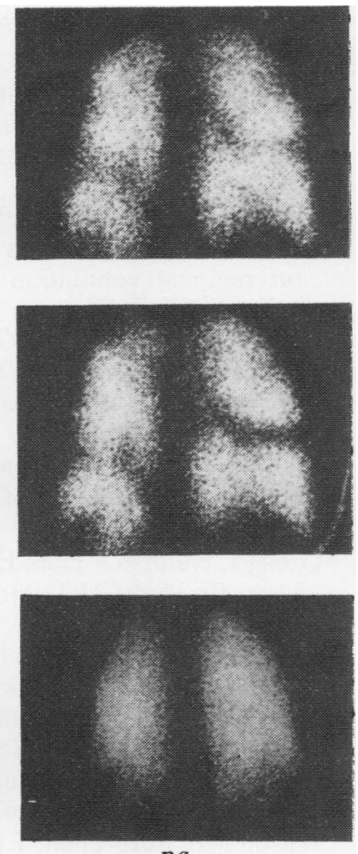

$p a$

Fig 2 Example of regional disturbances in ventilation, shown by ${ }^{81 m} \mathrm{Kr}$ imaging during different stages of bronchodilator treatment in a 46-year-old asthmatic woman. ap = anterior projection, $p a=$ posterior projection. The pictures show that after isoprenaline inhalation regional disturbances do not diminish but, in fact, worsen in some areas despite a substantial improvement in PEF. Only after intensive treatment did the distribution become uniform. A: basal PEF $250 \mathrm{l} / \mathrm{min}$; B: after isoprenaline PEF $315 \mathrm{l} / \mathrm{min}$; $C$ : after intensive treatment PEF $475 \mathrm{l} / \mathrm{min}$.

acute isoprenaline inhalations, ${ }^{29}$ although overall obstruction is substantially reduced, as indicated by the increase in PEF. In two patients ventilatory defects even intensified to some extent after isoprenaline administration (fig 2). It is evident that inhaled isoprenaline aerosol does not reach obstructed peripheral bronchi readily. ${ }^{16}$ It concentrates the bronchodilating effect of isoprenaline mainly on fairly large bronchi, which make the principal contribution to airways resistance. As regional perfusion defects were somewhat smaller than regional ventilation defects after administration of isoprenaline, the main type of regional mismatch was a decreased ventilation-perfusion ratio. This may reflect the earlier observations that hypoxaemia often persists after acute bronchodilator medication in asthmatic patients. ${ }^{210}$ The disturbances found in the ventilation-perfusion ratio are contrary to those found in pulmonary embolism, in which the ratio is as a rule increased in the affected area. ${ }^{67}$
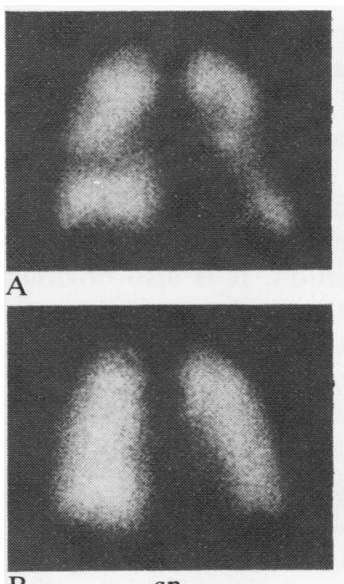

$\mathrm{B} a p$
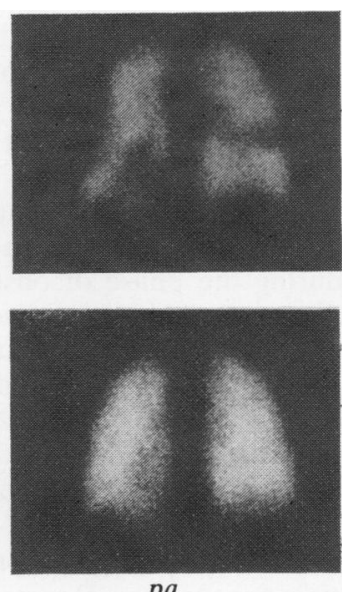

$p a$

Fig 3 Example of defects in regional perfusion, shown by ${ }_{99 m}^{T}$ T macroaggregate imaging, in the same patient and during the same bronchodilatation test as in fig 2. Abnormal regions of perfusion after isoprenaline inhalation correlate with disturbed regions of ventilation, the latter being slightly more severe in some areas. After intensive bronchodilator treatment the distributions are almost uniform. A: after isoprenaline PEF $315 \mathrm{l} / \mathrm{min} ; B$ : after intensive treatment PEF $475 \mathrm{l} / \mathrm{min}$.

The notable improvement in regional ventilation after intensive bronchodilator treatment, with additional improvement of PEF values, indicates that besides further bronchodilation of larger airways there was also appreciable dilatation of the segmental and smaller bronchi that were obstructed earlier. Although the individual PEF values were restored to normal after intensified treatment, slight nonuniformity in ventilation could be detected in $87 \%$ of the patients. No patient, however, showed more serious regional disturbances at this stage. These findings imply that many asthmatic patients receiving continuous medication may have some pulmonary areas of delayed ventilation even during remissions.

The notable reversal of regional perfusion disturbances after intensive bronchodilator treatment reflects the physiological and reversible nature of the disturbances. ${ }^{17-19}$ This is also confirmed by the finding that perfusion disturbances, both before and after intensive treatment, were for the most part situated in the same areas as the disturbances in ventilation and were only slightly more limited than those found in cases of ventilation-perfusion mismatching. Even after the intensive treatment for one week, however, $40 \%$ of patients had mild disturbances in ventilation-perfusion ratios that could contribute to hypoxaemia. ${ }^{210}$ It is not possible to determine on the basis of the present results 
whether isoprenaline or the other sympathomimetic drugs administered also had a direct vasodilator effect in the regions of disturbed circulation, although such an effect has been seen in animal experiments. ${ }^{20}$

The results indicate that asthmatics as a rule have regional disturbances in ventilation and perfusion during the phase of obstruction. It is also obvious that acute inhaler treatment cannot remedy the regional disturbances in pulmonary function, despite appreciable alleviation of overall bronchial obstruction. Intensive bronchodilator treatment, however, seems to diminish considerably the regional disturbances of both ventilation and perfusion.

This study has been supported by Finnish Foundation for Allergy Research and the Sigrid Jusélius Foundation.

\section{References}

${ }^{1}$ McFadden ER Jr, Lyons HA. Airway resistance and uneven ventilation in bronchial asthma. J Appl Physiol 1968;25:365-70.

${ }^{2}$ Demedts M, De Roo M, Devos O, Billiet L, Cosemans J. Effect of bronchodilation on regional lung function measured by ${ }^{133} \mathrm{Xe}$ and gamma camera. Eur $\mathrm{J}$ Nucl Med 1977;2:9-12.

${ }^{3}$ Schor RA, Shames DM, Weber PM, Remedios LVD. Regional ventilation studies with $\mathrm{Kr}-81 \mathrm{~m}$ and $\mathrm{Xe}-133$. A comparative analysis. J Nucl Med 1978;19:348-53.

4 Taplin GV, Tashkin DP, Chopra SK, et al. Early detection of chronic obstructive pulmonary disease using radionuclide lung-imaging procedures. Chest 1977;71:567-75.

${ }^{5}$ Fazio F, Palla A, Santolicandro A, Solfanelli S, Fornai E, Giuntini C. Studies of regional ventilation in asthma using ${ }^{81 \mathrm{~m}} \mathrm{Kr}$. Lung 1979;156:185-94.

${ }^{6}$ Harf A, Meignan M. Computation of regional ventilation-perfusion ratio. An aid to the diagnosis of pulmonary embolism. Bull Europ Physiopath Resp 1980;16:299-308.

${ }^{7}$ Lavender JP, Cunningham DA. Clinical value of krypton-81m and technetium-99m perfusion lung scanning. Bull Europ Physiopath Resp 1980;16:309 20.

${ }^{8}$ Fazio F, Lavender JP, Steiner RE. ${ }^{8 \mathrm{~m}} \mathrm{Kr}$ Ventilation and ${ }^{99 m} \mathrm{Tc}$ perfusion scans in chest diseases. Comparison with standard radiographs. Am J Roentgenol 1978;130:421-8.

9 Sovijärvi ARA, Virjo A, Pöyhönen L, Muittari A, Vauramo E. Demonstration of effects of bronchodilation on regional ventilation in obstructive lung diseases using $\mathrm{Kr}^{81 \mathrm{~m}}$ and gamma camera. Annales Universitatis Turkuensis, Series D 1977;8:58-62.

${ }^{10} \mathrm{Knudson}$ RJ, Constantine HP. An effect of isoproterenol on ventilation-perfusion in asthmatic versus normal subjects. J Appl Physiol 1967;22:402-6.

${ }^{11}$ Fazio F, Jones T. Assessment of regional ventilation by continuous inhalation of radioactive krypton-81m. $\mathrm{Br}$ Med J 1975;iii:673-6.

${ }_{12}$ Gregg I, Nunn AJ. Peak Expiratory flow in normal subjects. Br Med J 1973;iii:282-4.

${ }^{13}$ Bentivoglio LG, Beerel F, Bryan AC, Stewart PB, Rose B, Bates DV. Regional pulmonary function studies with xenon ${ }^{133}$ in patients with bronchial asthma.J Clin Invest 1963;42:1193-200.

${ }^{14}$ Heckscher T, Bass H, Oriol A, Rose B, Anthonisen NR, Bates DV. Regional lung function in patients with bronchial asthma. J Clin Invest 1968;47:1063-70.

${ }^{15}$ Wilson AF, Surprenant EL, Beall GN, Siegel SC, Simmons DH, Bennett LR. The significance of regional pulmonary function changes in bronchial asthma. Am J Med 1970;48:416-23.

${ }^{16}$ Dashe CK, Ponto RA, Ganapes CM, Drage CW, Kronenberg RS. The distribution of nebulized isoproterenol and its effects on regional ventilation and perfusion. Am Rev Respir Dis 1973;107:869-73.

${ }^{17}$ Rahn H, Bahnson HT. Effect of unilateral hypoxia on gas exchange and calculated pulmonary blood flow in each lung. J Appl Physiol 1953;6:105-11.

${ }^{18}$ Cournand A. Pulmonary circulation. Its control in man with some remarks on methodology. Science 1957;125: 1231-43.

19 Tauber K, Keyssler H, Parhofer R. Ueber die Blutverteilung in der Lunge bei mangelhafter Sauerstoffversorgung eines Lappens. Muench Med Wochenschr 1958;100:1106-12.

${ }^{20}$ Reyes A, Sykes MK, Chakrabarti MK, Tait A, Petrie A. The effect of salbutamol on hypoxic pulmonary vasoconstriction in dogs. Bull Eur Physiopath Respir 1978;14:741-53. 